\title{
LA MATERIALIDAD DEL
}

SONIDO

Palabras clave

Sonido, audio, realización audiovisual, producción audiovisual, televisión

\section{Los valores expresivos de la}

\section{sustancia sonora}

\section{Esteban Manuel Stepanian Taracido}

Realizador de televisión. Profesor Asociado de la Universidad Carlos III. Profesor Adjunto de de la Universidad Antonio de Nebrija.

Facultad de Humanidades, Comunicación y Documentación. Universidad Carlos III. Edificio Ortega y Gasset C/ Madrid 13328903 Getafe (Madrid) Email: estepani@hum.uc3m.es, stepanian@telefonica.net

\section{Resumen}

La investigación sobre los procesos de producción sonora en la creación de obras audiovisuales afectan, en términos generales, a cuestiones exclusivamente tecnológicas. Para valorar su rendimiento expresivo en la construcción del discurso es imprescindible que, de forma paralela, esta investigación se aborde también desde la perspectiva de la realización audiovisual.

Para ello es necesario asumir que los conceptos básicos en los que se fundamenta el desarrollo tecnológico no han de ser necesariamente esenciales en los estudios que se plantean desde puntos de vista creativos.

En particular es oportuno someter a examen el concepto de fidelidad y reivindicar las posibilidades emotivas, e incluso significantes, de formatos de producción sonora hoy en desuso.
Key Words

Sound, Audio, Audiovisual Production, Television, Television Network

\footnotetext{
Abstract

Generally speaking, research on sound production processes creating audiovisual works affects exclusively technological matters. But to evaluate their expressive performance in audiovisual discourses research must be framed in terms of the audiovisual production.

Therefore it is necessary to assume that the basic concepts in which the technological development is based are not essential in the studies generated from creative point of views.

Specially, it is adequate to examine the fidelity concept and claims the emotional and significant possibilities of sound production formats that are nowadays out of use.
} 


\section{Introducción}

La llegada de la tecnología digital al ámbito de la grabación, la reproducción y la transmisión sonora en televisión ha conllevado un sinfín de ventajas objetivas que hoy ya nadie está en condiciones de poner en duda. La mejora en los parámetros técnicos del sonido y la posibilidad de transportar la señal digital por variados canales sin que ésta sufra pérdidas audibles constituye una revolución absoluta frente a los actualmente superados procedimientos analógicos.

Resuelto pues, por el momento, el problema de la calidad del audio monoaural, la investigación se dirige entonces a establecer las condiciones técnicas que permitan reproducir ambientes sonoros preservando la espacialidad acústica que un oyente percibiría si se situase en un lugar privilegiado del acontecimiento sonoro que se pretende grabar o transmitir. Lugar privilegiado que, en términos semióticos, no es más que la posición del enunciatario, en tanto que espectador ideal -en este caso, oyentepropuesto por el texto audiovisual a quien se dirige la película de cine, la retransmisión de determinado evento deportivo o espectáculo musical.

Por primera vez, al espectador ideal de una determinada construcción audiovisual se le asigna, en el propio texto, un lugar espacial desde el que contemplar y escuchar el acontecimiento. Independientemente del lugar que ocupe en su espacio real, se trate de su sala de estar, de su habitación o de su despacho de trabajo, los sistemas de sonido envolvente proponen, en términos sonoros, la posición desde la que el espectador debe disfrutar el texto. Es más, en muchas ocasiones diseñan una posición ideal interna al propio texto, como sucede cuando la grabación de un concierto de música culta se realiza considerando como posición ideal de escucha, el lugar que ocupa cualquiera de los miembros de la orquesta: el violín concertino, el ejecutante de un oboe o el propio director ${ }^{1}$.

A pesar de la notable novedad que esta posibilidad técnica supone y de sus innegables consecuencias en el ámbito semiótico, es preciso reconocer que esta demanda, hoy satisfecha, no es nueva. Ya Rudolf Arnheim (1980:42), en un interesante conjunto de reflexiones acerca del todavía joven medio radiofónico señalaba, en la década de los 30 del pasado siglo, esta carencia en la transmisión de audio:

En las retransmisiones de acontecimientos, donde resulta mucho más difícil de aclarar la situación del oyente, suele producirse una sensación insatisfactoria. Para el radioyente la situación resulta confusa y sólo capta parte del acontecimiento que se produce en un espacio grande; es verdad que experimenta gracias al sonido la amplitud del espacio, el confuso griterío de la gran masa humana; pero parece como si todos los sonidos proce- 
dieran de una misma dirección; sólo se establece diferencia entre fuertes y débiles, claros y confusos. Se exige mucho a la capacidad intuitiva del radioyente.

Desde entonces, y hasta hace bien pocos años, únicamente la introducción del sistema de captación y registro en estéreo supuso una respuesta a la insatisfactoria sensación que percibía Arnheim. Pero, en los últimos tiempos y gracias a las facilidades de tratamiento que la señal digital ofrece, se han desarrollado todo tipo de investigaciones encaminadas a mejorar esa percepción espacial del oyente. Y este monográfico es sin duda la mejor prueba de ello.

Se trata de que el espectador/ oyente pueda percibir en la butaca de su salón la "imagen" sonora tridimensional - o tetradimensional si valoramos la relación de intensida- des de las fuentes - que el aparato de producción de audio está en condiciones de captar en un lugar de "lo real"; ${ }^{2}$ la relación espacial de sonidos que allí crean las diversas fuentes sonoras.

Frente al tradicional objeto de estudio que constituía el audio o sonido, individualmente considerado, se impone ahora, el polimórfico y complejo concepto de imagen sonora espejo de una imagen acústica previa. Y, previsiblemente, frente al tradicional audio que alcanzaba al oyente de manera lineal y con un valor puramente informativo, se impondrá ahora el concepto de umwelt ${ }^{3}$ sonora que añade a su valor informativo toda la carga simbólica y sobre todo emotiva inherente a los ámbitos sonoros.

\section{Objetivos}

En paralelo al innegable desarrollo que ofrecen hoy, y ofrecerán en el futuro, las técnicas digitales de captación y emisión de audio envolvente, es absolutamente necesario que exista una investigación que aborde estos procesos, ligados a la realización de productos audiovisuales, en sus aspectos expresivos y emotivos. Y ello de manera autónoma a la investigación propia de los procesos tecnológicos que la susten$\tan$.

Respaldar esta demanda es el primero y más general objetivo de este trabajo. Una investigación no opuesta pero sí independiente que debe situar la posición del realizador al lado de la del ingeniero de sonido de igual forma que, en el terreno del vídeo, se sitúa al lado de la del director de fotografía o de la del operador de cámara.

Así, y de manera particular, se pretende demostrar también que las características sonoras ligadas a los diversos sistemas de toma y grabación de sonido -a los formatos de grabación en definitiva-, que en términos tecnológicos no son más que efectos indeseables a eliminar -ruido interno-, 
poseen valores expresivos y emotivos útiles a la realización audiovisual que es preciso investigar.

Por último, y en esta línea, es objeto también de este estudio proponer un procedimiento que permita que se pongan en práctica, a la hora de crear productos audiovisuales, los resultados de esta demandada investigación sobre los valores expresivos del formato sin que ello implique la renuncia, como es obvio, a la deseable e ineludible evolución tecnológica.

\section{Metodología}

Para completar los objetivos propuestos se comienza por discutir el concepto de fidelidad. La fidelidad concepto clave y central en la investigación tecnológica debe de ser cuestionado y matizado al afrontar la producción sonora desde un punto de vista creativo. Se comprueba que proceder de este modo abre nuevas expectativas de análisis.

Tras ello se examinan los conceptos de sustancia sonora y materialidad del sonido, a la luz de las aportaciones de los escasos investigadores que han abordado la cuestión desde ámbitos no exclusivamente técnicos, y se evidencian sus capacidades expresivas en la construcción de productos audiovisuales. Cotejar la opinión de expertos o autoridades es metodológicamente práctica probatoria habitual y tradicionalmente aceptada.
Tras centrar las características que se han vinculado a los aspectos físicos del sonido, se constata que el desarrollo digital acarrea un proceso de homogeneización que pone en riesgo precisamente su rendimiento expresivo.

Finalmente se demuestra la posibilidad de recuperar las características sonoras de formatos previos a la comprobada homogeneización digital; restaurando así todo su universo de evocaciones expresivas y emotivas asociadas que, desde luego, resultan muy útiles a la praxis de la realización audiovisual.

Se trata, esta última, de una demostración por construcción en la que se propone un modelo capaz de dar cuenta de las exigencias que la hipótesis teórica impone. 


\section{La fidelidad}

La investigación tecnológica que actualmente ha desembocado en los sistemas de sonido envolventes y que finalmente ha permitido la creación de esta imagen sonora compleja está presidida, como lo ha estado siempre, desde que los antiguos micrófonos de carbón consiguieron transducir por primera vez, la voz humana en impulsos eléctricos, por el concepto de fidelidad. Y es normal que así haya sido. Nada hay más natural para un ingeniero de sonido que pretender reproducir el sonido grabado y transmitido de la manera más semejante al sonido original .

Sin embargo, y a pesar del consenso que suscita, desde el punto de vista de la realización ${ }^{4}$ de audio el concepto de fidelidad debe de ser rigurosamente sometido a examen si aspiramos, como no puede ser de otro modo, a agotar las posibilidades expresivas que el nuevo aparato tecnológico nos ofrece. Sería lamentable volver a incurrir en el error que, por omisión, condujo a los realizadores a saludar alborozados la emisión de audio dual en los canales de televisión y a despreciar las posibilidades expresivas que la producción de audio estéreo ofrece. Pues todavía hoy, cuando la captación, la grabación y la transmisión en estéreo es un hecho habitual en la mayoría de los canales profesionales de televisión del mundo, en nuestro país es muy poco habitual que los realizadores utilicemos de manera consciente la pano- ramización del sonido en la creación de productos audiovisuales ${ }^{5}$.

Desgraciadamente hemos de constatar nuevamente que, en nuestro ámbito de estudio, el trabajo de los ingenieros al ofrecernos nuevos instrumentos expresivos va muy por delante del uso que de ellos hacemos en contextos profesionales reales. El concepto de fidelidad a la fuente debe ser sometido a examen porque, si bien es primordial para el trabajo de los ingenieros, puede por el contrario constituir un obstáculo para el desarrollo de las posibilidades expresivas del audio envolvente.

Cuando se trata de grabar, transmitir y reproducir sonido es esencial, desde el punto de vista técnico, que la señal final reconstruida en las cajas acústicas sea "suficientemente similar" a la señal acústica que excitó los micrófonos al inicio del proceso. Cuando esto es así admitimos que la señal final es fiel a la original. La preocupación por mantener esta fidelidad a la fuente llevó al Instituto Alemán de Normalización a fijar en 1973 los valores máximos de respuesta en frecuencia, distorsión y ruido admisibles para establecer el concepto de alta fidelidad (hi-fi) que a partir de entonces pasó a constituir el estándar de calidad de los equipos de audio doméstico o de consumo. Hoy la persecución de este objetivo sigue centrando la mayor parte de las investigaciones en torno al sonido grabado. 
Es normal y deseable, lo hemos dicho ya, que así sea.

Sin embargo, perseguir la fidelidad excluye, por propia definición, la investigación en algunos de los ámbitos de trabajo en los que, previsiblemente, más se han de desarrollar las posibilidades expresivas que ofrecerán los nuevos sistemas de audio envolvente.

En particular, y entre otros, en la creación de espacios (o imágenes) sonoro(a)s virtuales. Es obvio que una vez que estamos en condiciones de reproducir un ambiente sonoro determinado estamos también en condiciones de crear ambientes perfectamente pregnantes pero que no se correspondan con imágenes acústicas reales. Hace ya mucho tiempo que la televisión ha descubierto las posibilidades que la toma de imagen y el montaje ofrecen en la creación -que no reproducción- de los espacios propios del discurso ${ }^{6}$. El trabajo de construcción espacial que se propone al espectador en la transmisión televisiva de una etapa de cualquier carrera ciclista es un ejemplo contundente.

Sin duda, con relación al audio las cosas habrán de ir por el mismo camino y en su momento será ineludible reflexionar sobre ello.

Por el momento, insistimos, si se pretende avanzar en el conocimiento de ciertos valores expresivos del sonido, es necesaria la puesta en crisis del concepto de fidelidad. Escuchemos la reflexión que este concepto sugería ya a mediados del siglo pasado a Pierre Schaeffer (1996: 47), el padre e ideólogo de la llamada "música concreta"; con seguridad el movimiento musical que de manera más insistente reivindicó el valor estético de la propia materialidad del sonido:

Una orquesta toca en una sala; más tarde, esa misma orquesta toca en un disco, para un oyente en su propia casa. Todo, desde el aspecto técnico al comercial, se conjura para convertir al oyente en el propietario de esa orquesta, en su propio domicilio; no habrá que extrañarse, pues, de que se haya puesto el acento en una especie de convención social sobre la «fidelidad», y que no se haya sacado nada en claro sobre la "transformación» que representa la sustitución de un campo sonoro por otro.

Y es que efectivamente, el mito tecnológico de la fidelidad no hace sino enmascarar la condición básica y esencial en la que se fundamenta la realización de un producto audiovisual. Trátese del producto de que se trate: programa de televisión o una transmisión de audio, en la mayoría de las ocasiones la creación audiovisual construye un objeto nuevo con ciertos materiales desviados en lo real. Si acaso, en las pocas situaciones en las que la exigencia de respeto al modelo original es mayor, como pueda ser el caso de las retransmisiones deportivas, la realización en realidad propone una reelaboración de materiales previos (Stepanian 2002). 
Y es precisamente esta particularidad del proceso de producción audiovisual la que le ofrece sus posibilidades expresivas.

Por lo tanto, para avanzar en la investigación desde el punto de vista de la realización, para hacernos cargo del significado de la transformación de un espacio sonoro por otro y agotar las posibilidades expresivas que esta transformación conlleva, una vez creado el instrumento tecnológico, no cabe sino aparcar el concepto de fidelidad, o al menos desalojarlo del lugar central que ocupa, para sustituirlo por el de la libertad manipulativa del espacio sonoro. Para un realizador el espacio sonoro creado y sus características no han de ser necesariamente similares a las originales sino únicamente verosímiles y coherentes con el discurso que se "trae entre manos"; con el discurso que pretende construir. Con este convencimiento y en ese contexto se inscribe la propuesta fundamental de este trabajo.

\section{La sustancia sonora}

Una de las consecuencias derivadas de la expansión de las tecnologías digitales ha sido la tendencia a homogeneizar las sustancias sonoras de los sonidos grabados o transmitidos. La digitalización, como consecuencia de su propio proceso técnico, ha traído consigo una estandarización de la materia sonora y con ello se han perdido las características propias de los diversos sistemas de grabación y transmisión analógi$\cos$.

Desde luego que expresiones como sustancia sonora o materialidad del sonido no parecen fácilmente definibles y lo primero que cabe plantearse si se pretende ser mínimamente objetivo, lo que en un trabajo de estas características es irrenunciable, es si estas expresiones son pertinentes en un ámbito científico.

La cuestión no es, desde luego, inmediata pero cierto es también que algunas opinio- nes autorizadas -las mismas que si bien no nos ayudan a definirlas sí contribuyen a caracterizarlas- parecen respaldar su uso.

Michel Chion (1998:111) en el completo análisis que ha dedicado estudiar las relaciones entre la imagen y el sonido introduce, refiriéndose a éste último, la expresión "indicios materializadores” que:

“... son los que nos remiten al sentimiento de la materialidad de la fuente y al proceso concreto de la emisión del sonido. Son susceptibles, entre otras cosas, de darnos informaciones sobre la materia (madera, metal, papel, tejido) causante del sonido, así como la manera en que éste se mantiene (por frotamiento, choques, oscilaciones desordenadas, vaivenes periódicos, etc.)

Roland Barthes (1986: 265) ha introducido la expresión "grano de la voz" para referirse a las características de la voz humana que se sitúan fuera de: 
En resumen, todo lo que, en la ejecución, está al servicio de la comunicación, la representación, la expresión: aquello de lo que normalmente se habla, lo que forma el tejido de los valores culturales (gustos confesados, modas, discursos críticos), lo que se articula directamente sobre las coartadas ideológicas de una época (la "subjetividad", la "expresividad”, el "dramatismo", la "personalidad" de un artista).

Para Barthes el grano de la voz es la presencia en ella del cuerpo del cantante con las características propias de su aparato fonador, aunque advierte (Barthes, 1986: 268): El "grano" de la voz no es -o no lo es tan sólo- su timbre. Pues sólo la voz cuando canta, cuando dice, cuando entra en relación con una lengua posee grano. Y no por lo que dice, no por el mensaje, sino por los propios sonidos de esa lengua.

Sin duda, en su peculiar y atractivo estilo de escritura, Roland Barthes incide sobre esa característica física de la voz, a la que el propio autor ha denominado también textura (Barthes, 1986: 252).

La voz que canta, ese precisísimo espacio en que una lengua se encuentra con una voz y deja oír, a quien sepa escuchar, lo que podríamos llamar su" textura": la voz no es el aliento, sino más bien esa materialidad fónica que surge de la garganta, el lugar en que el metal fónico se endurece y se recorta.

Pues bien no parece difícil, el propio Barthes invita a ello, extender el concepto de "grano" de la voz al de "grano" del soni- do para referirnos a esas propiedades materiales o texturales del sonido, que se sitúan más allá - ¿o quizá deberíamos decir "más acá” para ser más precisos?- de sus valores comunicativos o expresivos para situarse en un ámbito marcadamente emotivo.

Propiedades éstas que son, en primera instancia, consecuencia del propio aparato o sistema productor del sonido: el aparato fonador del hablante; la frotación de la cuerda del arco; el rozamiento de un gozne no engrasado; etc. Si además se pretende que estos sonidos, con su "grano", o con sus "indicios materializadores", sean tratados por un sistema de procesamiento de audio habrá que admitir que sean captados por micrófonos; grabados en diversos formatos; y en su caso, emitidos o transportados por variadas tecnologías.

Habrá que admitir, en definitiva, que sean procesados por un sistema mediador que debido a sus propias características tecnológicas, entregue al espectador/oyente sentado en su butaca un sonido acústico con un "grano" diferente a su vez del "grano" del sonido acústico captado en origen.

En segunda instancia, el aparato de tratamiento electrónico del sonido contribuirá también, a su manera, a conformar la "textura" del sonido acústico escuchado.

No es sino lo que Pierre Schaeffer (1956: 53) ponía de manifiesto cuando resaltaba la importancia que en su propuesta de música concreta era obligado reconocerle al timbre del aparato. Al analizar los aspectos propios 
de la transformación sonora que sufre un sonido acústico tras atravesar una cadena de captación, grabación y/o emisión para convertirse, según su propia terminología, en un objeto sonoro "constatamos que incluso en ese caso, el propio aparato da su propia "factura» a la reproducción". Y efectivamente, esa característica que más adelante define como "firma específica que se puede atribuir globalmente al aparato concreto que se utiliza" no es más que esa peculiaridad física, material, que cada uno de los aparatos mediadores en la cadena analógica de audio confiere al sonido original. Es la textura que aporta el formato.

\section{El formato de la imagen}

A quien mantenga sus reservas respecto de la utilización de la expresión "formato del sonido" cabría replicarle que "formato de la imagen” sí es una expresión de uso habitual.

Desde que en 1816 ó 1822, quizá 1826 ó 1827 (a estas alturas la polémica parece propia de historiadores desocupados) Nicéphore Niépce realizara la primera fotografía sobre peltre o betún de judea -tampoco hoy está aún muy claro- (Soguez, 1994) en sólo cincuenta años se sucedieron vertiginosamente los materiales y los formatos en los que se ha registrado la imagen captada por un objetivo (Sánchez, 1997:12):

En 1839 Louis Daguerre fija la imagen sobre una plancha sensible de cobre (daguerrotipo) tras media hora de exposición. [...] En 1840 William Henry Fox Talbot desarrolla el calotipo, que fija una imagen en breve tiempo de exposición (dos minutos frente a los veinte habituales). En 1847 Abel Niepce de Saint Victor redacta el primer método práctico para conseguir negativos en un cristal. [...]

En 1851 F. Scott Archer utiliza colodión húmedo, un material sensible que hace posibles las instantáneas con pocos segundos de exposición. Entre 1855 y 1868 se experimenta y comercializa el celuloide, y a partir de 1880 se cuenta con un producto mucho más estable que el colodión húmedo, la gelatina-bromuro.

Ya entonces los fotógrafos comenzaron a ser conscientes de las peculiaridades que el tipo de material usado para fijar la luz aportaba a la imagen óptica que se formaba en el cuerpo de la cámara. Y desde entonces, y paulatinamente, a cada uno de los formatos se les ha ido asociando determinados valores expresivos que como tal, son generalizables, y muchos valores emotivos que lógicamente aunque se generen en un contexto común, son propios de cada espectador.

Quien conserve alguna foto antigua de los miembros de su familia o de su lugar de 
nacimiento lo podrá suscribir sin reservas, especialmente quien tenga la suerte de conservarla en su formato original.

Exactamente lo mismo ha ocurrido con la colección de formatos que se han sucedido a lo largo de la historia del cine. En este caso los valores expresivos no sólo se han impuesto de manera espontánea sino que los propios directores se han ocupado de explotarlos al máximo.

Así, en trabajos especialmente delicados existía la posibilidad elegir un formato $\mathrm{u}$ otro en función de los determinados valores expresivos que la calidad de imagen ofrecía. Y es indudable que estos valores expresivos estaban, y están, fuertemente ligados al poder de evocación que en el espectador despierta la materialidad de la imagen.

Es conocida la anécdota en la que Sven Nykvist $^{7}$ (1962) relata sus experimentos con diversas emulsiones para satisfacer a un Bergman que pretendía que su película $E 1$ silencio $^{8}$ se apareciese ante el espectador como un sueño presentando, frente al uso que la tradición imponía por entonces, imágenes de muy alto contraste:

Bergman believes in photography having high contrast, so my preparations for this dream effect began with a series of experiments with different kinds of film emulsions. We were surprised to discover the strong graininess effect we obtained from our experiments with $16 \mathrm{~mm}$ Ektachrome Commercial blown up to $35 \mathrm{~mm}$ black-and-white.
We also made photographic tests with ordinary sound recording film and with orthochromatic emulsions, and, all these tests included the films of various manufacturers ${ }^{9}$.

Es evidente que cuando Bergman y Nykvist llegan incluso a plantearse rodar en película para registro sonoro no pretenden decirle expresamente al espectador: "Mira, estoy utlilizando un tipo de película que te debe provocar una determinada impresión" pero cierto es que, sin decirlo, buscaban provocarla. A través del formato, buscaban inducir un efecto emotivo en los espectadores del film.

Cuando la imagen óptica pasó a ser registrada en soportes magnéticos, las cosas se desarrollaron de igual manera y todavía hoy algunos realizadores añoramos los suaves matices de color, y de transición entre luces, que para algunos trabajos nos ofrecía el viejo Betacam SP frente a las intensidades y homogeneidades lumínicas que imponen los actuales formatos basados en tecnología digital.

Se constata entonces que, refiriéndonos al vídeo, a términos como textura, materialidad o grano, que son de uso común y se manejan con absoluta normalidad, se les reconoce una función expresiva en la construcción de la obra audiovisual.

Realicemos una pequeña abstracción y admitamos ya definitivamente que, a pesar de la resistencia que nos produce si lo referimos al audio, -resistencia basada únicamente en la inferior consideración en que, 
en la mayoría de los casos, tenemos al audio frente al vídeo en nuestro proceso perceptivo, y la menor consideración que recibe en nuestros planes de estudios o de formación-, es perfectamente posible y productivo aludir al formato sonoro y a conceptos tales como el de la materialidad del sonido para constituirlos en objeto de estudio.

\section{La homogeneización textural del sonido}

Autorizados pues a manejar términos como sustancia, textura, grano o fisicidad del sonido, que aún sin definir exactamente, son ya fácilmente asimilables por el lector, podemos concluir teniendo en cuenta lo hasta ahora expuesto, que el aparato mediador aporta una materialidad característica al sonido que depende en primera instancia del grano del propio sonido originario, pero también, en gran medida, de las características tecnológicas de cada uno de los aparatos que intervienen en dicho sistema mediador.

Así las cosas, lo que aquí se pretende sostener es que esas características texturales del sonido - captado, grabado y emitido- vehiculan una serie de valores emotivos y expresivos. Una serie de valores cuyo estudio será impertinente para un ingeniero de sonido que se deba exclusivamente a la fidelidad pero que, sin embargo, sí deben ser tenidos en cuenta por el ingeniero que asuma los aspectos creativos de su trabajo; y muy especialmente por los realizadores que pretendan preservarlos en la construcción de su relato audiovisual.

$\mathrm{Y}$ es momento ahora de reivindicarlos porque es precisamente ahora cuando la estandarización textural que acarrea la tecnología digital los pone en peligro.

Propongamos un caso práctico: la transmisión analógica del audio ambiente y locución de competiciones deportivas $\mathrm{y}$ en particular de partidos de fútbol provocaba que, debido al sonido microfónico de entonces, la transmisión por línea telefónica y otras pérdidas en las diversas etapas que atravesaba, la calidad del sonido, tal y como hoy la entendemos, fuese "grosso modo" inversamente proporcional a la distancia a la que la retransmisión deportiva se producía. De manera que esta "deficiencia” en el audio invitaba ya al espectador a considerar la distancia que lo separaba del evento, con la carga emocional que en determinadas épocas tenía sentarse a ver ¡en directo!, un partido de fútbol que en ese instante se jugaba al otro lado del mundo. Era algo así como si la propia "deficiencia" técnica del audio fuese prueba, e informase al espectador, de la "proeza técnica” que el canal de televisión estaba llevando a cabo. El espectador, inconscientemente, elevaba la categoría del evento. La calidad del audio, su textura, inducía a través del sistema emotivo de quien lo disfrutaba 
un plus de significación al acontecimiento. Sugería una clave de lectura.

Actualmente la calidad del audio (y en consecuencia su materialidad) es similar en todas las retransmisiones deportivas. Y será absolutamente igual cuando se generalice la transmisión digital. Nada en el sonido indicará a un espectador español que el partido que estamos viendo se está jugando en Valladolid o en Buenos Aires.

Personalmente deploro profundamente perder la experiencia del audio característico de los "partidos lejanos" pero cierto es que, en definitiva, esto no es más que una reminiscencia melancólica de viejo espectador.

Quizá la misma con la que Chion (1998: 99) evoca aquellas salas cinematográficas de su niñez en las que era perceptible:

Por una parte el "lloriqueo" del sonido, debido a una velocidad inestable del deslizamiento - que se percibía sobre todo en los pasajes musicales- $y$, por otra parte, una resonancia cavernosa y lejana, a causa de la escasa calidad de la reproducción sonora, pero también de la reverberación que la acústica de la sala otorgaba a las voces de los actores.

Gracias a lo cual, al contrario de lo que sucede en las modernas salas equipadas con el sistema $\mathrm{THX}^{10} \mathrm{y}$ diseñadas para combatir hasta el límite los efectos de la reverberación, todavía se experimentaba el sentimiento de su dimensión real.
Efectivamente. Son recuerdos subjetivos e individuales de viejo espectador, pero es que se trata precisamente de esto.

Es innegable y generalizable que de un modo u otro la mejora técnica ha hurtado a la audiencia la fuente de información y sobre todo de evocación que constituía la propia materialidad del sonido.

A la luz de lo expuesto es fácil entender también una vieja polémica que desde otros puntos de vista se presenta como absolutamente absurda.

Es conocida la discusión que en su momento provocó, y que en ciertos ámbitos aún hoy subsiste, la llegada del disco compacto de audio.

Por un lado, se encontraban los que, con toda razón, defendían su apabullante superioridad técnica frente a los tradicionales discos de vinilo. Por el otro, subsistían grupos de "románticos" -así se les adjetivaba en la época- que insistían en la mejor calidad del audio grabado en vinilo. En realidad no discutían sobre lo mismo. En ninguno de los parámetros que miden la calidad del audio había comparación posible. El sonido que ofrecía la grabación digital era notablemente mejor.

¿Qué animaba, entonces, a los "románticos" a proclamar la superioridad del vinilo? Pues precisamente el hecho de que la, en su momento, "perfecta” grabación digital excluía las características propias con las que el vinilo materializaba el sonido y a las que se asociaba todo el universo de evoca- 
ciones expresivas y emotivas al que los "románticos" no estaban dispuestos a renunciar.

Era esto exactamente lo que se perdía. Los valores emotivos y expresivos exclusivamente ligados al formato de grabación; ligados a la peculiar materialidad, a la fisicidad con la que el formato dotaba al sonido grabado. Era el roce de la aguja con el disco. Era el timbre del formato... o de la vía... o del canal de transmisión.

$\mathrm{Y}$ es que, efectivamente, de modo genérico, la cuestión también se plantea en estos términos: el formato evoca. Determinados soportes, determinadas vías de transmisión provocan, siquiera de manera inconsciente -y así debe de ser- fuertes valores emotivos en el espectador.

Sin embargo la revolución digital debido a su esencia técnica tiende a homogeneizar la textura sonora. Un audio digital produce sonidos acústicos con una materialidad similar y en consecuencia se hurtan al espectador esos valores emotivos y en muchos casos expresivos ligados al formato.

La situación parece no tener salida. No es técnicamente deseable, ni económico, ni desde luego razonable en modo alguno, oponerse a la calidad y a las posibilidades de tratamiento y manipulación que ofrece la tecnología digital, pero es lamentable, desde el punto de vista creativo, perder la inmensa fuente de emociones que durante más de un siglo han provocado los distintos sistemas de registro y transmisión del sonido.

Cierto es que desde el punto de vista técnico, es posible objetar, adelantémonos ya a ello, que las posibilidades de la producción digital son suficientes para preservar las características de los formatos anteriores. Independientemente de cómo los oyesen sus contemporáneos, la voz de Enrico Caruso o de Carlos Gardel es hoy para nosotros absolutamente inseparable de las características que a esa voz le confería la grabación en discos de cera. Probablemente seríamos incapaces de identificar a Caruso, a Gardel o a cualquier cantante de los que exclusivamente conservemos grabaciones históricas si tuviésemos la posibilidad de grabarlos con las técnicas de las que hoy disponemos. Lo que escuchamos hoy no es la voz de Gardel, sino su símbolo cargado de referencias. Y a la grabación digital actual no le queda otro remedio que regrabar, transmitir o en definitiva manejar ese símbolo, que como tal, preserva su poder evocativo.

Pero cierto es también que, fuera de los limitados ejemplos a los que en este sentido nos podamos referir, la tendencia es precisamente la contraria. Se trata de mejorar, de reducir ruidos, de "tapar" defectos... Es lógico, es un trabajo muy estimulante si nos situamos en la perspectiva del ingeniero. 


\section{El efecto audio: una solución al problema}

La objeción que se ha planteado parece indicarnos, sin embargo, una buena vía de solución para el conflicto.

Volvamos por un momento al ámbito del vídeo. Al igual que sucede con el sonido la irrupción de los formatos digitales ha igualado en gran medida las "calidades" de imagen, pero inmediatamente se han desarrollado fórmulas para que las posibilidades expresivas ligadas a la fisicidad de la imagen se preserven. Y hoy en día cualquier generador de efectos digitales, lineal o no-lineal, nos ofrece herramientas específicas para que la imagen que manipulamos se presente como una imagen de cine antiguo, como una imagen de la televisión de $\operatorname{los} 70$, como una imagen de videoaficionado...

Así, todos conocemos ejemplos de series de ficción que ambientadas en un determinado momento histórico, además del trabajo específico de dirección artística con el que se sitúa el tiempo de la acción, ofrecen una textura de imagen que rememora los formatos de grabación o filmación usados en la época para despertar en el espectador todo el universo de evocaciones que ese formato, es decir esa calidad de imagen, ese aspecto del color -o del blanco y negrole provoca. ${ }^{11}$
La imagen digital se presenta "como" la imagen de cine antiguo. La simula. No la suplanta. Nadie mínimamente formado que vea esa imagen pensará que está ante una imagen cinematográfica; pero la imagen digital manipulada despertará en él el todo el universo de evocaciones al que le remitía la imagen fílmica.

La imagen digital manipulada está en el lugar de la imagen fílmica real. Es también un símbolo y en cierta medida podemos asegurar que paulatinamente, estamos creando el "código de la materialidad de la imagen". Es decir, manipulamos la imagen digital (por definición tendente también a la homogeneidad técnica) para rentabilizar los valores expresivos que hemos asociado históricamente a la calidad, a la materialidad, al formato de la imagen.

Pues es ésta y no otra la solución al problema que respecto al audio se ha planteado en las páginas anteriores y que constituye finalmente, el objetivo de este trabajo. Reivindicar la elaboración, por la vía del efecto, de un código de la materialidad del sonido.

Pero de una materialidad no necesariamente ligada a la especificidad física del aparato emisor. Porque en la reproducción de la textura del sonido original, "la fidelidad" sí debe jugar un papel fundamental. Eviden- 
temente cuanto más fiel en términos técnicos sea un sistema de captación, registro y/o emisión de audio, más posibilidades tendrá de recrear las características texturales del sonido original. Más capacitado estará para preservar el "grano" del sonido a lo largo de toda la cadena de audio.

Lo que aquí se propone no es recrear un código de la materialidad del sonido original sino de la materialidad del sonido grabado, transmitido o, en definitiva, procesado por una determinada cadena de audio atendiendo a las características que le ha conferido precisamente esa, y no otra, cadena de audio.

Y defender los valores expresivos y emotivos que, en este sentido, está en condiciones de proveer una postproducción de audio.

Se trata de que, sin afectar a la calidad del audio, la sustancia sonora recreada nos evoque la distancia a la que se juega en la realidad el partido de fútbol que disfrutamos cómodamente en el salón de nuestra casa.

Esto evidentemente no sólo es perfectamente compatible con cualquier sistema de audio envolvente sino que es además absolutamente complementario.

Planteemos el siguiente problema de realización. En una película de ficción ambientada en los años veinte del pasado siglo suena un gramófono en una fiesta que se celebra en el amplio salón de una mansión.
La película se produce para ser proyectada con sistemas de sonido envolvente que en la escena a la que hacemos referencia sitúan al espectador en el centro de la fiesta que en la ficción se está desarrollando. La música diegética que suena en el gramófono ha sido compuesta "originalmente" para la película "a la manera" de cierta música festiva de los años locos.

¿Alguien duda de que aún trabajando con los mejores sistemas de audio, o quizá precisamente por ello, esa música original deba de ser sometida a un proceso de postproducción de audio que la dote de la textura propia del sonido del gramófono?

Es cierto que siempre se podrá grabar en disco y reproducir en alguno de los gramófonos que todavía hoy nos quedan para luego efectuar una toma de sonido con la máxima fidelidad.

Pero honestamente, parece mucho más productiva, y desde luego interesante, la investigación que nos puede devolver los perdidos valores emotivos de las grabaciones y las transmisiones antiguas por vía del efecto.

Imagínese por un momento la riqueza sonora de una producción con sonido envolvente en el que las sustancias sonoras sean diversas. En el que la textura de cada sonido nos remita a su proceso de captación, grabación o transmisión. El sonido de una televisión, de un tocadiscos, del teléfono con sus micrófonos de carbón... 


\section{Conclusiones}

- La investigación tecnológica aplicada a los procesos de producción, grabación y emisión sonora de obras audiovisuales aventaja sensiblemente a los estudios que pretenden examinar las nuevas posibilidades expresivas que de ella se podrían derivar.

- En el origen del problema se sitúa la tendencia a importar los conceptos claves de la investigación tecnológica al ámbito de la investigación que se aborda desde la perspectiva de la realización audiovisual.

- La puesta en crisis del concepto de fidelidad es fundamental para valorar el rendimiento del sonido en el proceso de creación de la obra audiovisual.

- Las propiedades texturales del sonido, debidas a las peculiaridades del aparato productor o a las de los dispositivos de captación, grabación, transmisión y emisión, portan unos valores expresivos y emotivos esenciales en la construcción del discurso audiovisual.

- La revolución que ha acarreado la tecnología digital al servicio de la producción de audio fomenta la homogeneiza- ción de la sustancia sonora, tiende a abolir las diferencias texturales de los diversos sonidos suprimiendo la huella de su origen y de la cadena de audio que los transforma. Consecuentemente elimina el universo de evocaciones que este proceso puede provocar en el espectador.

- Puesto que este proceso es irreversible (y no sería deseable que no lo fuese) la labor de realización audiovisual debe demandar de la investigación tecnológica que resuelva el problema, al igual que sucede en el caso del vídeo, por la vía de la simulación, creando los efectos de audio adecuados que permitan recuperar los valores expresivos y emotivos ligados al formato de producción.

- El enriquecimiento intrínseco con el que dota a una producción audiovisual un sistema de sonido envolvente debe completarse con el diseño individual de la sustancia sonora, expresivamente justificada, de cada una de las fuentes individuales de audio que intervienen en la mezcla final. 


\section{Referencias}

ARNHEIM, RUDOLF (1980): Estética radiofónica. Barcelona. Gustavo Gili.

BARTHES, ROLAND (1986): Lo obvio y lo obtuso. Barcelona. Paidós.

\section{CHION, MICHAEL,}

- (1998a): La audiovisión. Barcelona. Paidós

- (1998b): E1 sonido. Música, cine literatura...

Barcelona. Paidós

DAYAN, DANIEL y KATZ, ELIU (1995): La

historia en directo. La retransmisión televisiva de los acontecimientos. Barcelona. Gustavo Gili.

NYKVIST, SVEN (1962): "Photographing The Films Of Ingmar Bergman”. Publicado en American Cinematographer. $\mathrm{n}^{\circ} 613$. Octubre, 1962.
SÁNCHEZ VIDAL, AGUSTÍN (1997): Historia del cine. Madrid. Historia 16.

SCHAEFFER, PIERRE,

- (1959): ¿Qué es la música concreta? Buenos Aires. Nueva visión.

- (1996): Tratado de los objetos musicales. Madrid. Alianza ed.

SOUGEZ, MARIE-LOUP (1994): Historia de la fotografía. Madrid. Cátedra.

STEPANIAN TARACIDO, ESTEBAN M.(2002): La televisión construcción lúdica contemporánea. Madrid. UCM. Tesis doctoral. Recurso electrónico http: / /www.ucm. es/BUCM/tesis/inf/ucmt25730.pdf

\section{Cita de este artículo}

Stepanian Taracido, E.M. (2009) La materialidad del sonido. Los valores expresivos de la sustancia sonora $R e$ vista Icono14 [en línea] 15 de Octubre de 2009, № 13. pp. 292-309. Recuperado (Fecha de acceso), de http://www.icono14.net

\footnotetext{
${ }^{1}$ En este sentido son muy interesantes las experiencias que lleva a cabo Manuel Sánchez Cid en el laboratorio experimental de sonido envolvente de la Universidad Rey Juan Carlos de Madrid. Parte del trabajo de este investigador se centra, concretamente, en inmersión sonora y toma de sonido multicanal.

${ }^{2}$ Coherentemente con nuestro trabajo anterior (Stepanian, 2002) preferimos la expresión "lo real" frente al término realidad porque realidad es el espacio sonoro creado por las fuentes originales pero también (¿por qué no?) la reproducción del espacio sonoro que se lleva a cabo en el salón del oyente. Con lo real, sin embargo, nos referimos específicamente (Stepanian, 2002: 126) a la "situación de lo existente en la realidad previamente al proceso constructivo" que constituye el proceso de producción televisiva. En este caso particular aludimos a la situación sonora previa (en sentido lógico, no temporal) a la colocación de los micrófonos que han de captarla y con los que se inicia el proceso.

${ }^{3}$ El término alemán umwelt se utiliza en psicología para referirse al entorno del individuo en sus aspectos más específicamente sensoriales y preceptúales, que son precisamente aquellos que pretendemos destacar aquí.

${ }^{4}$ Con el término realización nos referimos a la actividad por la cual estamos en condiciones de construir textos audiovisuales con un valor expresivo determinado haciendo uso del conjunto heterogéneo de materiales propios de la puesta en escena y puesta en panatalla audiovisual con arreglo a un principio u objetivo determinado. (Stepanian, 2002)
} 
${ }^{5}$ Parece increíble que en los múltiples programas de debate que se emiten en los canales de televisión españoles en los que los invitados ocupan un lugar preciso e invariable a lo largo de todo el programa, frente al necesario respeto a los ejes de acción que impiden que el espectador confunda sus posiciones, se produzca un desprecio absoluto por la localización espacial de sus voces que parecen provenir todas del centro del set, independientemente del lugar que el personaje ocupe en el espacio.

${ }^{6}$ Una amplia y muy interesante reflexión sobre ello se puede encontrar en Dayan y Katz, 1995.

${ }^{7}$ Sven Nykvist (Moheda, 1922- Estocolmo, 2006) Director de fotografía. Colaborador habitual de Ingmar Bergman.

${ }^{8}$ BERGMAN, INGMAR: Tystnaden (E1 silencio). 35 mm. B/N. Producción: Svensk Filmindustri, 1963.

9 "Bergman confía en la fotografía de alto contraste, así que la preparación para este efecto de sueño comenzó con una serie de experimentos con diferentes tipos de emulsiones. Nos sorprendió descubrir el marcado efecto de grano que obtuvimos experimentando con la película Ektachrome Commercial de 16mm. hinchándola a $35 \mathrm{~mm}$. en blanco y negro. También hicimos pruebas fotográficas con películas de registro sonoro y con emulsiones ortocromáticas. Todas ellas incluyendo películas de diferentes fabricantes.” Traducción del autor.

${ }^{10}$ Lucasfilm THX es un sistema de control de calidad de audio en las salas cinematográficas diseñado para asegurar unos criterios mínimos de fidelidad en la proyección.

11 “Cuéntame cómo pasó". Producción: Grupo Ganga. Emisión: TVE-1, 2001-hasta la actualidad. "Amar en tiempos revueltos”. Producción: Diagonal TV. Emisión: TVE-1, 2005-hasta la actualidad. 